\title{
Low Affinity Immunoglobulin Gamma Fc Region Receptor II-A
}

National Cancer Institute

\section{Source}

National Cancer Institute. Low Affinity Immunoglobulin Gamma FC Region Receptor II-A. NCI Thesaurus. Code C38553.

Low affinity immunoglobulin gamma Fc region receptor II-a (317 aa, 35 kDa) is encoded by the human FCGR2A gene. This protein plays a role in the endocytosis of opsonized antigens. 